\title{
BOUNDEDNESS FOR MULTILINEAR COMMUTATORS OF INTEGRAL OPERATORS IN HARDY AND HERZ-HARDY SPACES ON HOMOGENEOUS SPACES
}

\author{
CHEN XiAnyi AND LiU LANZHE
}

\begin{abstract}
In this paper, we shall study the Hardy-boundedness for the multilinear commutators related to the singular integral operators on the space of homogeneous type. By using the Hölder's inequalities and the $L^{q}(1<q<\infty)$ boundedness for the singular integral operators on the space of homogeneous type, we obtain the $\left(H_{\vec{b}}^{p}, L^{p}\right)$ and $\left(H \dot{K}_{q, \vec{b}}^{\alpha, p}, \dot{K}_{q}^{\alpha, p}\right)$ type boundedness for the multilinear commutators on the space of homogeneous type.
\end{abstract}

Mathematics subject classification (2010): 42B20, 42B25.

Keywords and phrases: Singular integral, multilinear commutator, BMO, Hardy space; Herz-Hardy space, space of homogeneous type.

\section{REFERENCES}

[1] J. Alvarez, Continuity properties for linear commutators of Calderón-Zygmund operators, Collect. Math., 49 (1998), 17-31.

[2] J. Alvarez, R. J. Babgy, D. S. Kurtz And C. PÉRez, Weighted estimates for commutators of linear operators, Studia Math., 104 (1993), 195-209.

[3] A. Bernardis, S. Hartzstein And G. Pradolini, Weighted inequalities for commutators of fractional integrals on spaces of homogeneous type, J. Math. Anal. Appl., 322 (2006), 825-846.

[4] J. J. BETANCOR, A commutator theorem for fractional integrals in spaces of homogeneous type, Inter. J. Math. \& Math. Sci., 6, 24 (2000), 419-421.

[5] M. BRAMANTI AND M. C. CERUTTI, Commutators of singular integrals and fractional integrals on homogeneous spaces, Harmonic Analysis and Operator Theory, Contemp. Math., 189, Amer. Math. Soc., 1995, 81-94.

[6] M. Bramanti-M. C. Cerutti, Commutator of singular integrals on homogeneous spaces, Boll. Un. Mat. Ital. B (7) 10 (1996), 843-883.

[7] W. CHEN AND E. SAWYER, Endpoint estimates for commutators of fractional integrals on spaces of homogeneous type, J. Math. Anal. Appl., 282 (2003), 553-566.

[8] R. Coifman, R. Rochberg And G. Weiss, Factorization theorem for Hardy space in several variables, Ann. of Math., 103 (1976), 611-635.

[9] J. Garcia-Cuerva AND M. L. Herrero, A Theory of Hardy spaces associated to Herz Spaces, Proc. London Math. Soc., 69 (1994), 605-628.

[10] I. Genebashvili, A. Gogatishvili, V. Kokilashvili and M. Krbec, Weighted theory for integral transforms on spaces of homogeneous type, Piman Monogr. and Surveys in Pure and Appl. Math., 92, Addison-Wesley/Longman, 1998.

[11] S. Z. Lu, Four lectures on real $H^{p}$ spaces, World Scientific, River Edge, NI, 1995.

[12] S. Z. LU AND D. C. YAnG, The decomposition of the weighted Herz spaces and its applications, Sci. in China (ser. A), 38 (1995), 147-158.

[13] S. Z. LU AND D. C. YANG, The weighted Herz type Hardy spaces and its applications, Sci. in China (ser. A), 38 (1995), 662-673.

[14] C. PÉREZ, Endpoint estimate for commutators of singular integral operators, J. Func. Anal., 128 (1995), 163-185. 
[15] C. PÉREZ AND G. PRADOLINI, Sharp weighted endpoint estimates for commutators of singular integral operators, Michigan Math. J., 49 (2001), 23-37.

[16] C. PÉREZ AND R. TRujillo-GonZALEZ, Sharp Weighted estimates for multilinear commutators, J. London Math. Soc., 65 (2002), 672-692.

[17] G. PRAdolini, O. Salinas, Commutators of singular integrals on space of homogeneous type, preprint, available at http://math.unl.edu.ar/preprints/.

[18] E. M. STEIn, Harmonic Analysis, real variable methods, orthogonality and oscillatory integrals, Princeton Univ. Press, Princeton NJ, 1993. 